\title{
Smart Crop Protection System from Animals
}

\author{
M. Jaya Prabha, R. Ramprabha, V. Vasu Brindha, C. Asha Beaula
}

pests and damage by animals leading to lower yields. Ancient strategies are being followed by farmers aren't much effective and it's not being feasible to hire guards to keep an eye fixed on the crops and forestall the wild animals. Therefore this zone is to be monitored continuously to prevent entry of this kind of animals or the other unwanted intrusion[1]. So, animal detection system is being vital in farm areas.

\begin{abstract}
Crops in farms are many times damaged by animals like buffaloes, cows, goats, birds and wild elephants. This causes major losses for the farmers. Farmers can not stay on the field for 24 hours and protect it. To overcome this problem, an animal detection system has been designed to detect the presence of animals and it offres a warning and divert the animal without any harm. The designed system will continuously check for any animal to enter the field. IR sensors and ultrasonic sensor are used in this project to detect animal movement and to give a signal to the controller. Further the animals are being divereted by generating sound and signals, and this signal is being transmitted to GSM and instantly give farmers warning, so the farmers will be aware of the difficulty and available to the spot just in case the animals do not show off by the alarm. The complete safety of crops was ensured by this system from animals thus protecting the farmer's loss.
\end{abstract}

Keywords: Animal detection, GSM module, IR sensor, Ultrasonic sensor.

\section{INTRODUCTION}

India is an agrarian region. Agriculture has perpetually been India's most significant economic sector. While most of India's population is dependent on agriculture, the farmers still experience many issues. Due to overpopulation a deforestation occurs, water, food and shelter in forest areas are lacked by deforestation. Therefore, intrusion of animals in residential areas is being rising day by day which is being affecting the human life, property that creates conflict between human and animals. Agriculture is the backbone of the economy, however, would result in massive crop loss due to animal intrusion in agricultural land. Elephants and other animals being coming into contact with humans have a negative impact in the several ways, such as crop destruction, damage to food stores, water supply, homes and other properties, injury and human death. Conflict between human beings may also be a serious problem where large quantities of money are wasted and life is at risk. In recent times the numbers of those types of conflicts are increasing. Farmers in India has been facing serious threats from natural calamities,

Revised Manuscript Received on April 25, 2020.

* Correspondence Author

M. Jaya Prabha*, Electronics and Communication Engineering National Engineering College, Kovilpatti, India. Email: mjp8699@gmail.com

R. Ramprabha, Electronics and Communication Engineering, National Engineering College, Kovilpatti, India. Email: prabha260799@gmail.com

V. Vasu Brindha, Electronics and Communication Engineering, National Engineering College, Kovilpatti, India. Email: vasubrindha1999@gmail.com

C.Asha Beaula, Electronics and Communication Engineering, National Engineering College, Kovilpatti, India. Email: ashajulusnec@gmail.com

(C) The Authors. Published by Blue Eyes Intelligence Engineering and Sciences Publication (BEIESP). This is an open access article under the CC BY-NC-ND license (http://creativecommons.org/licenses/by-nc-nd/4.0/)

\section{OBJECTIVE}

- The main objective is to protect the crops in farm area from animals.

- IR sensor detects the animal while crossing it, by sensing the movement of the animal and ultrasonic sensor detects the birds entering in the fields.

- This system will continuously check for any animals entering inside the field.

\section{RELATED WORK}

Most of the farmers in India using electrical fence to guard the crops. However, this system has some issues like occasionally voltage drop occurs and the owners of the fence has been got to check the voltage however they cannot know it without being going there and this system is harmful to the animals[2].

\section{PROPOSED SYSTEM}

In the proposed system, Crop monitoring is done by placing sensors in the agricultural field. In our proposed work, IR, ultrasonic sensor and GSM is used. When animals come near to the IR sensor and it detects the animal movement. After getting that initial input signal, it will be given to the microcontroller for further processing and the system will be activated immediately, it will on the APR board, and the sound is being played to divert the animal, at the same time it makes a call to the owner. Similarly ultrasonic sensor is mounted on the motor. It rotates 360 degree, therefore ultrasonic sensor detects the presence of birds in all direction[3]. If the ultrasonic senor is detected, it sends the signal to the controller. Microcontroller block is used for reading the inputs from IR and ultrasonic sensor. Whole process is controlled by microcontroller. The GSM module is used for making call to farmer when movement is detected. It alerts the farmer that some animals or birds try to enter into the farm. The Fig. 1 shows the block diagram of the proposed smart crop protection system from animals using Arduino Uno.

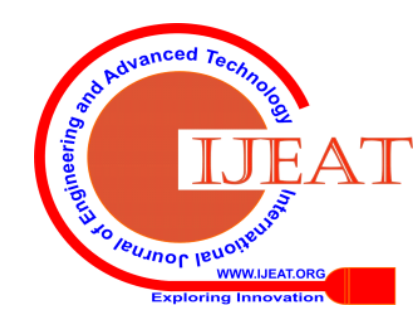




\section{Smart Crop Protection System from Animals}

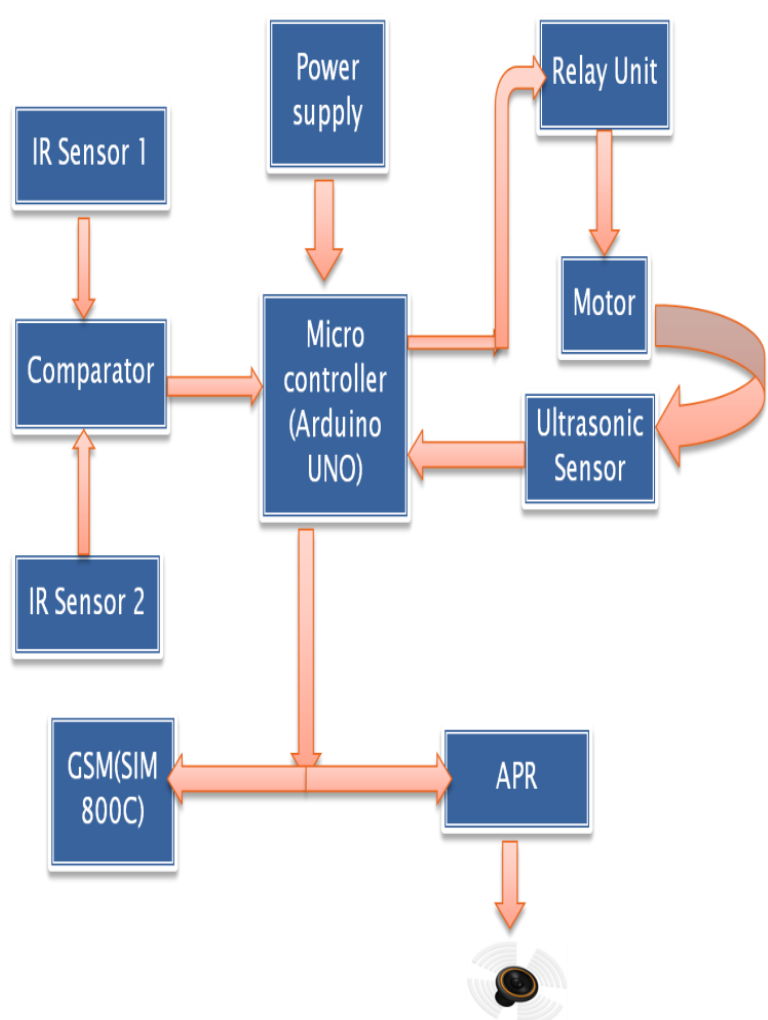

Fig .1. Block diagram for smart crop protection system

The proposed system is classified into four parts - DC power supply part, sensor part, controlling part, alarm part.DC power supply part consists of an ac supply of 230v is step down using a transformer, bridge rectifier converts ac signal to dc and the voltage regulator is used to produce constant dc voltage. The sensor part consists of two IR sensors and one ultrasonic sensor. This part senses the movement of animals and birds. Next controlling part which consists of a comparator which receives input from the IR sensor, it gives constant voltage and feeds the Arduino with the signal. The Arduino UNO also forms part of the controlling unit and makes necessary processing regarding the indication of the intruder. The Arduino also drives a relay driver which in turn controls the motor for rotating the ultrasonic sensor in 180 degrees clockwise and 180 degrees anticlockwise for the detection of birds. Finally, the alarm part consists of a GSM module which makes a call to the farmer and speaker which produces sound to scare the animals.

\section{HARDWARE}

\section{A. Arduino Uno}

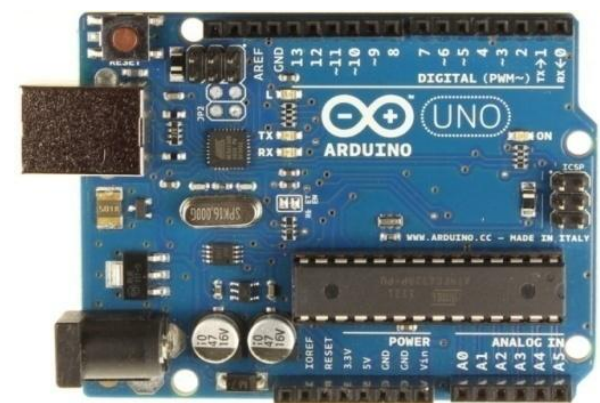

Fig. 2. Arduino Uno Microcontroller AT Mega 328P
Arduino Uno ATmega328P is a microcontroller board. It has fourteen digital input/output pins (of that six may be used as PWM outputs), six analog inputs, a sixteen megahertz quartz crystal, a USB connection and reset button.

Digital Inputs: Every of which give or take up $40 \mathrm{~mA}$ current. Some of them have special functions like pins zeros and one, that is being acting as Rx and TX severally,and for the serial communication, a pair of pins and 3 of which are external interrupts, pins 3,5,6,9 and 11 that provides pulsewidthmodulation output and pin thirteen wherever light-emitting diode has been connected.

Analog inputs: Six analog input/output pins, every providing a resolution of ten bits.

\section{B. IR Sensor}

An IR sensor could be a device that is used to detect the IR radiation being falling on that. It is essentially a tool that consists of an IR light-emitting diode and a photodiode that square measure output together known as a photo-coupler or an opto-coupler[7]. The IR light-emitting diode emits IR radiation, intensity of reception by the photodiode which dictates the output of the device.

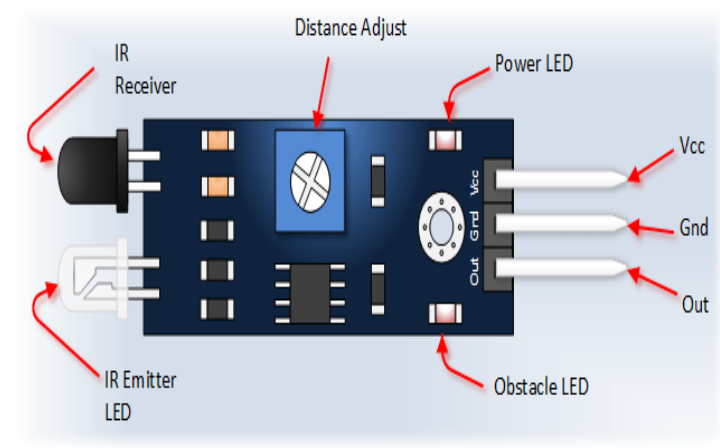

Fig. 3. IR Sensor

\section{Ultrasonic Sensor}

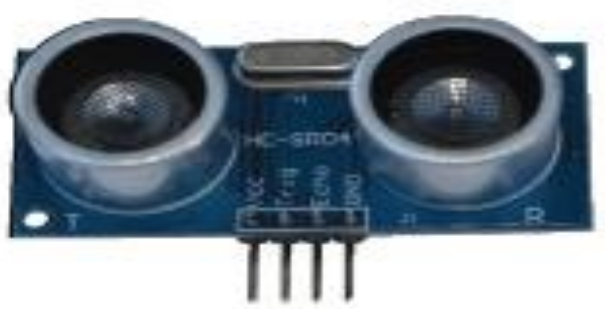

Fig. 4. Ultrasonic Sensor

Ultrasonic sensors are primarily a sound sensors; however they are being operated at a frequency higher than a human hearing. The device sends a sound wave at a specific frequency. It is then being listened for that specific sound wave to bounce off of associate object and causing the sound wave and also the sound wave being returning. If you recognize how briskly one thing goes and the way long it's movement you'll notice the gap.

\section{DC Gear Motor}

A geared DC Motor has a gear assembly given to the motor. RPM is being defined as the

Published By:

Blue Eyes Intelligence Engineering \& Sciences Publication

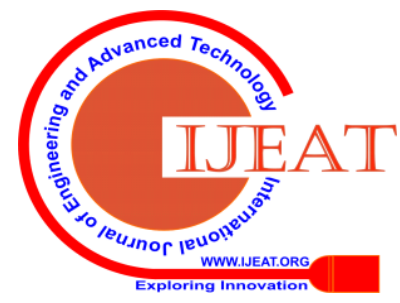


rotations of shaft per minute which is being used to measure the speed of the motor. The speed of the motor has been reduced with the help of gear assembly, which increase the torque to drop the speed. The correct arrangement of gears in a gear motor has been used to reduce speed at any required specification. This concept of being dropping the speed with the help of gears and extent the torque is called as gear reduction.

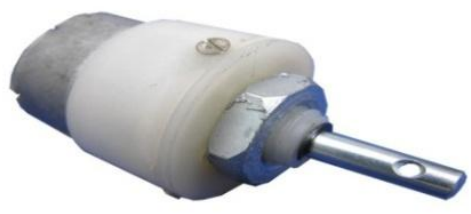

Fig .5. DC Gear motor

\section{E. VOICE MODULE}

Voice Recorder is a device which is helpful for many occasions like meetings, lectures, interviews, conferences, broadcasts etc., to capture the voice. From that we will play them back or edit easily. There are various forms of hardware and computer code dedicated to voice recording that give many customization choices. In this project, Voice Recorder Modules explains in the electronics hobbyist community. Among the various categories of voice module, the powerful audio processor is featured in apr33A with superior audio ADC's and DAC's. The apr33A3 voice recorder have the simple key trigger and with the help of switch ,the message can be record and playback by the users. In apr33A3,user can record maximum of eight voice message(s), it's appropriate within the easy interface or got to limit the length of one message, e.g. leave messages system, toys, electronic devices, etc.,

\section{F. RELAY}

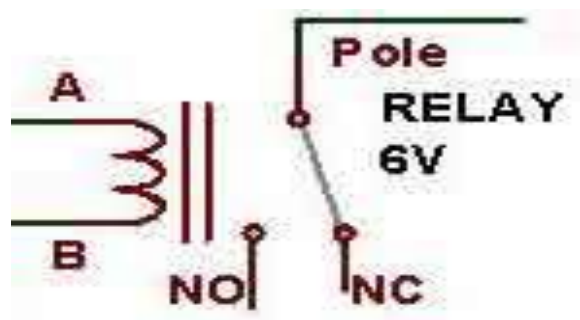

Fig .6. Circuit diagram for relay A magnetic flux is generated by the current flowing through the coil of the relay, which attracts a lever and changes the switch contacts. The relays have two switch positions based on the coil current that is on or off and this is called as double throw or changeover switches. The relay's switchconnections are usually labeled as COM(POLE), NC(Normally Close) and NO(Normally Open). COM/POLE means Common, which indicates NC and NO always hook up with this, it's the moving a part of the switch.NC means Normally Closed, which indicates COM/POLE is connected when the relay coil is not magnetized. NO means Normally Open, which indicates COM/POLE is connected to this when
A relay is also called as electrically operated switch.

the relay coil is magnetized and vice versa. The two basic operations of relays are high voltage application and the other is low voltage. Mostly to reduce the noise of the entire circuit, relays are used in low voltage applications. Relays are designed to scale back a phenomenon called arcing for high voltage applications.

\section{G. LM324 DRIVER}

The LM324 device works like a comparator which consists of four independent operational amplifiers having high-gain and internally frequency-compensated designed to function over broad range of voltages from a single power supply. It performs operation even when the split power supplies are used and the low power supply current drain is independent of the magnitude of the supply voltage. Application areas include transducer amplifiers, DC gains blocks and every the quality op amp circuits which are now much easier to put in in single power supply systems. For example, the LM124 series is usually operated directly off the quality $+5 \mathrm{~V}$ power supply voltage utilized in digital systems and without additional $\pm 15 \mathrm{~V}$ power supplies, it gives essential electronic interfaces easily.

\section{H. POWER SUPPLY MODULE:}

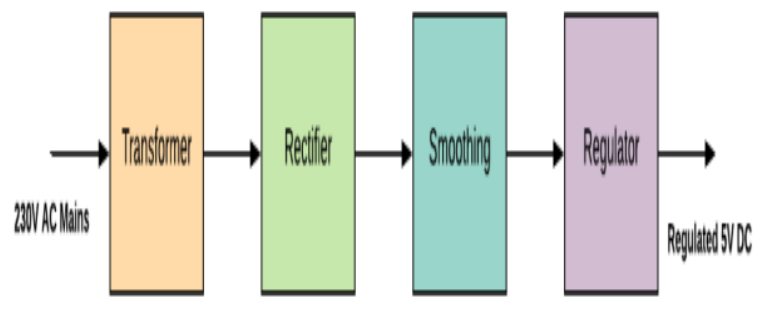

Fig .7. Block diagram for power supply

As we know without the power source any innovation of up to date technology cannot be initiated. Therefore it this quick paced world we have a tendency to deliberately want an accurate power supply which might be apt for a particular demand. The source section is vital one for circuit operation. It provides demand power offer for each one blocks and it turn out constant DC voltage. All the electrical equipments ranging from transistor to Intel IC's solely work with a DC starting from +-five volt to -+twelve volt. We have a tendency to square measure utilizing for identical, the foremost price effective and usually accessible energy supply of $230 \mathrm{~V}-50 \mathrm{~Hz}$ and stepping down, rectify, filter the unwanted ripples and regulating the voltage.

AC to DC power conversion consists of,

- Transformer: Steps the home line voltage up or down as required.

- Rectifier: converts AC voltage to a variable DC voltage.

- Filter: sleek the rhythmic DC voltage to a variable Dc voltage.

- Regulator: fastened the output voltage to constant worth.

\section{RESULT}

Once the animal or bird is detected, the speaker will be on and the recorded sound is

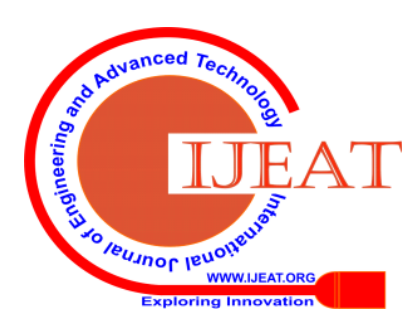




\section{Smart Crop Protection System from Animals}

played for 20 seconds and GSM module makes a call to the farmer. Along with the call, repellent system of irritating loud noise like cracker sound is used simultaneously with interval of 4 seconds is used upon the animal. This system works continuously for better effectiveness for protecting the crops from animals.

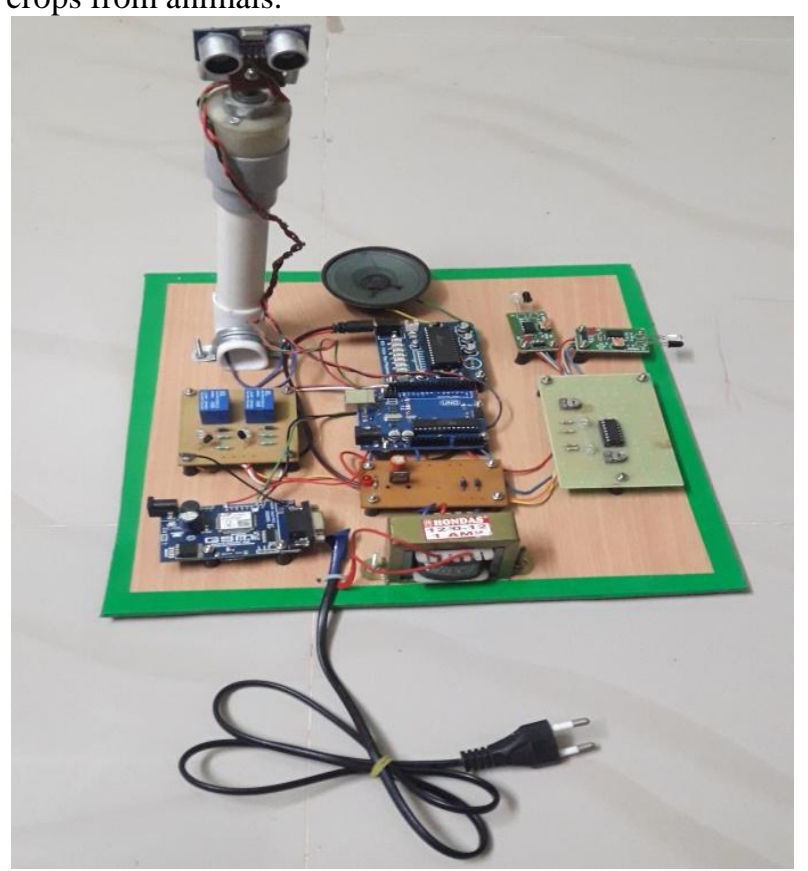

Fig .8. Shows the prototype of smart crop protection system

\section{CONCLUSION}

Farmers encounter severe threats in rural parts of India like damage done by birds and animals. Hence, to overcome this issue we have designed a system in which sound is played to scare the animals and birds, so that it will automatically run away. The GSM module makes a call to the farmer to alert him. Therefore, the designed system is affordable and useful to the farmers. The designed system won't be harmful to animals and person , and it protects the farm areas.

\section{FUTURE ENHANCEMENT}

In the future, there will be a large scope for this system. The IR sensors and Ultrasonic sensors are used to collect the information and transmitted through GSM. This project is further enhanced by wireless sensor network.The type of sensors like finding the moisture content of the soil, growth of the crop and nutrition content in the soil. These sensors gather informations which is useful to the farmers and able to conscious of the farm land from anyplace in the world.

\section{REFERENCES}

1 Wang, Z., Wang, H., Liu, L., Song, W., \& Lu, J. (2015, December). Community alarm system design based on MCU and GSM. In 2015 4th International Conference on Computer Science and Network Technology (ICCSNT) (Vol. 1, pp. 859-862). IEEE.

2 Shende, P. Y., Raut, S. M., Ingale, P. S., Nagose, A. K., Katakpur, P. S., \& Kathane, S. S. Solar Electric Fencing for Irrigation of Animal Man Conflict

3 Mohammad, T. (2009). Using ultrasonic and infrared sensors for distance measurement. World Academy of Science, Engineering and Technology, 51, 293-299

4 Volume:01 Pages:859-862, DOI:10.1109/ICCSNT.2015.7490876 , IEEE Conference Publications.
5 Amin, N., \& Borschbach, M. (2015, December). Quality of obstacle distance measurement using ultrasonic sensor and precision of two computer vision-based obstacle detection approaches. In 2015 International Conference on Smart Sensors and Systems (IC-SSS) (pp. 1-6). IEEE.

6 Pages:1-6,DOI:10.1109/SMARTSENS.2015.7873595IEEE

Conference Publications

7 Mustapha, B., Zayegh, A., \& Begg, R. K. (2013, December). Ultrasonic and infrared sensors performance in a wireless obstacle detection system. In 2013 1st International Conference on Artificial Intelligence, Modelling and Simulation (pp. 487-492). IEEE.

8 DOI: 10.1109/IECON.2013.6700389 CITED BY: PAPERS (1)

9 Frankiewicz, A., \& Cupek, R. (2013, November). Smart passive infrared sensor-Hardware platform. In IECON 2013-39th Annual Conference of the IEEE Industrial Electronics Society (pp. 7543-7547). IEEE.

10 Discant, A. Rogozan, C. Rusu and A. Bensrhair, "Sensors For Obstacle Detection" 2007 30th International Spring Seminar on Electronics Technology (ISSE), Cluj-Napoca, 2007, pp. 100-105. doi: 10.1109/ISSE.2007.44328

\section{AUTHORS PROFILE}

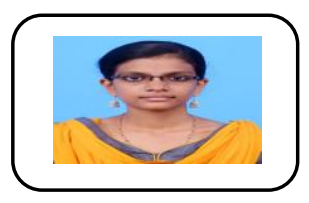

M. Jaya Prabha , was born in Tirunelveli, India in 1999 was currently pursuing her Bachelor of Engineering in National Engineering College, Kovilpatti, Tamil Nadu, India. She attended many technical workshops and participated in many events conducted by different colleges. She was a active member of IETE. Her research interest includes Device modeling and VLSI.She completed her mini project in the domain of VLSI.

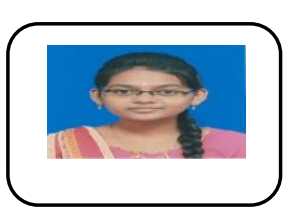

R. Ramprabha was born in Tuticorin, India in 1999 was currently pursuing her Bachelor of Engineering in National Engineering College, Kovilpatti, Tamil Nadu, India. She attended many technical workshops and participated in many events conducted by different colleges. She was a active member of IETE. Her research interest includes Device modeling and VLSI.She completed her mini project in the domain of VLSI.

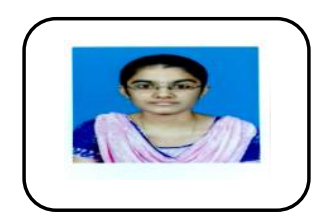

V. Vasu Brindha was born in Tuticorin, India in 1999 was currently pursuing her Bachelor of Engineering in National Engineering College, Kovilpatti, Tamil Nadu, India. She attended many technical workshops and participated in many events conducted by different colleges. She was a active member of IETE. Her research interest includes Device modeling and VLSI.She completed her mini project in the domain of VLSI.

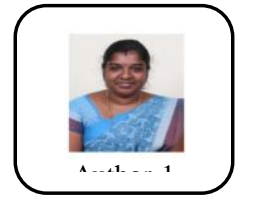

C. Asha Beaula, was born in Nagercoil, India in 1988. She received her bachelor's degree in Electronics and Communication Engineering from Anna University, Chennai, India in 2009. Then, she obtained her master's degree in Applied Electronics from Anna University, Chennai, India in 2011. In 2011, she joined in the Department of Electronics and Communication Engineering Unnamalai institute of technology, as a Lecturer. and in 2013 became an Assistant Professor at National Engineering College till now. Her research interests include Device modelling and 5G Wireless Communication. She has presented many research papers in various conferences. She is an institutional member of IEEE, and a fellow member of Indian Society of Technical Education (ISTE), Professional member at The Society of Digital Information and Wireless Communication(SDIWC).

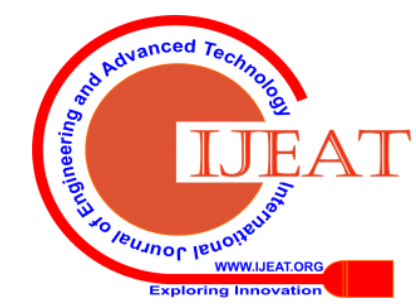

